\title{
On power quality and reliability of supply
}

\author{
Lidiia Kovernikova ${ }^{1 *}$, Roman Shamonov ${ }^{2}$ \\ ${ }^{1}$ Melentiev Energy Systems Institute SB RAS, Irkutsk, Russia \\ ${ }^{2}$ Public Joint Stock Company "Federal Grid Company of Unified Energy System”, Moscow, Russia
}

\begin{abstract}
Power quality determines reliability of electrical equipment operation, performance of the assigned functions by it, service life. In the last years problem of power quality attracted increased attention because of power quality degradation and a great number of consumer complaints. Many problems of power quality control, such as determination of liabilities and responsibility of power suppliers and consumers for its quality, call for solution. The paper presents the types of damages caused by harmonics and the results of an analysis of harmonic active power at the node connecting an aluminum smelter block to a supply network. The analysis is performed on the basis of measurements. Measured current and voltage were used to calculate harmonic active power. It was found out that the aluminum smelter block generates the harmonic active power to the supply network only during part of the measurement time. For the other part harmonic active power flows from the supply network to the aluminum smelter block. The paper presents the proposals on the use of harmonic active energy for determination of the power quality distortion source and its contribution.
\end{abstract}

\section{Introduction}

Power quality and supply reliability are closely interrelated. Power quality determines reliability of electrical equipment operation, performance of the assigned functions by it, service life. At the present voltage and its quality are the main parameter and index of power quality. In [1] voltage quality and supply reliability were combined into term - quality of supply, which is confirmed by practice of power system operation. In Russia before the adoption of the federal laws "On technical regulation" [2] and "On electric power industry" [3] the problem of power quality was treated as a problem of power system condition control. The power quality had to correspond to the requirements of the state standard [4]. The only barrier to meet its requirements consisted in absence of proper instruments for measuring the power quality indices. However, despite the lack of measuring instruments significant results were achieved in the area of power quality control. The top achievement is the adoption of two regulations, which formulated the economic mechanism of power quality control: "The rules of consumer connection to the public network in terms of the effect on power quality" [5], "The rules of applying the rate discounts and surcharges for power quality" [6]. Adoption of the law "On technical regulation" [2] made it possible not to fulfill requirements of the state standard on power quality, since the state standards were granted the status of documents of optional application. In the law "On electric power industry" [3] the necessity of the quality of power supplied to consumers, which complies with the technical regulations and other mandatory requirements, is indicated in more than ten clauses. However, as fairly noted in [7], it is done in the form of "general terms". Adoption of the law "On electric power industry" gave rise to emergence of many players of the electric power industry. Therewith, each of them solved the problems of satisfying own interests and the problem of power quality evolved into a secondary one. In the last few years this problem attracted increased attention because of power quality degradation and a great number of consumer complaints. Many problems of power quality control, such as determination of liabilities and responsibility of power suppliers and consumers for its quality, call for solution.

In the Customs Union countries the voltage quality requirements are specified in the GOST 32144-2013 [8]. Deviations in voltage characteristics from the rated ones lead to different adverse consequences for power suppliers and consumers.

\section{Examples of the adverse impact of poor quality voltage}

Interruptions of the supply voltage and dips. Voltage interruptions and dips arise as a result of short currents, connection of high power loads. The voltage dips can lead to spontaneous disconnection of contactors and magnetic starters [9] and, as a result, to interruption of power supply to consumers causing a technological damage. In [10] the continuous productions and sectors based on digital technologies are described as the most

\footnotetext{
Corresponding author: kovernikova@isem.irk.ru
} 
sensitive to voltage dips. In these branches the price of one dip is 2120-4682 EUR. On the average 13 voltage dips and 6 momentary voltage interruptions are observed annually at the node of load connection. Table 1 presents typical costs of voltage interruptions for different types of enterprises in one of the US states [11]. The cost rises by $2-4$ times with the increasing duration of voltage interruption up to 1 hour.

Table 1. Typical costs of momentary interruptions.

\begin{tabular}{|c|c|c|}
\hline \multicolumn{2}{|r|}{ Type of enterprise } & $\begin{array}{c}\text { Cost, } \\
\text { USD } / \mathrm{kW}\end{array}$ \\
\hline \multirow{8}{*}{ 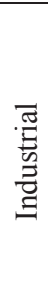 } & Paper & $1.5-2.5$ \\
\hline & Textile, metal fabrication, mining & $2.0-4.0$ \\
\hline & Rubber and plastics & $3.0-4.5$ \\
\hline & Petrochemical, food processing & $3.0-5.0$ \\
\hline & Pharmaceutical & 5.0 \\
\hline & Automobile manufacturing & $5.0-7.5$ \\
\hline & Electronics & $8.0-12.0$ \\
\hline & Semiconductor manufacturing & $20.0-60.0$ \\
\hline \multirow{3}{*}{ 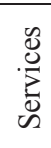 } & Communication & $1.0-10.0$ \\
\hline & Banks, hospitals, civil services & $2.0-3.0$ \\
\hline & $\begin{array}{l}\text { Restaurants, hotels, commercial } \\
\text { shops }\end{array}$ & $0.1-1.0$ \\
\hline
\end{tabular}

Voltage unbalance. In 2016 at one of the substations of the Volga-Don enterprise of the backbone networks the operation of gas protection resulted in tripping the $63000 \mathrm{kVA}$ transformer. The cause of the transformer tripping was a turn-to-turn fault in the primary winding that occurred because of quick insulation ageing because of the long-term current unbalance.

Harmonic voltage. The paper [12] presents the fact of damage of household appliances of consumers that was caused by tripping the $220 \mathrm{kV}$ transmission line "Pokosnoe - Tulun" in the Irkutsk region. The power was supplied to consumers over the transmission lines of 10 and $35 \mathrm{kV}$ from the $35 \mathrm{kV}$ buses of the substation "Pokosnoe". After tripping the $220 \mathrm{kV}$ transmission line at the substation "Pokosnoe" the values of the 11-th harmonic voltage factor $\left(K_{U(11)}\right)$ sharply increased. Their maximum values at phases $\mathrm{A}, \mathrm{B}$ and $\mathrm{C}$ reached $14.5 \%$, $17.2 \%$ and $14.4 \%$, respectively compared to the admissible value of $4 \%$. In the settlements situated at distances of 56, 87 and 101 kilometers from the substation "Pokosnoe" the maximum values of $K_{U(11)}$ proved to be $35.7 \%, 46.0 \%$ and $47.9 \%$, which caused the damage of household appliances.

Because of the harmonic problems the DC link at the substation "Mogocha" operated unsteadily. As indicated in [13], "due to availability of harmonic voltage of a high amplitude at a frequency of about $8 \mathrm{kHz}$ in the 35 $\mathrm{kV}$ network of converters the $35 \mathrm{kV}$ cable terminals were heated and damaged during commissioning works in the ring condition of power transmission between IPS of Siberia and IPS of East, which required additional elaboration of design options".

The harmonic currents caused the overheating of both phase and neutral wires of cable transmission lines. This problem is particularly vital in low voltage systems, where the single-phase loads are the harmonic sources. Even if the nonlinear loads turn out to be symmetric, considerable current can flow in the neutral wire primarily with the harmonics multiple of 3 . Figure 1 presents the curve of current variation in the neutral wire of the network for external lighting of the trading and entertainment center in the city of Krasnoyarsk [14].

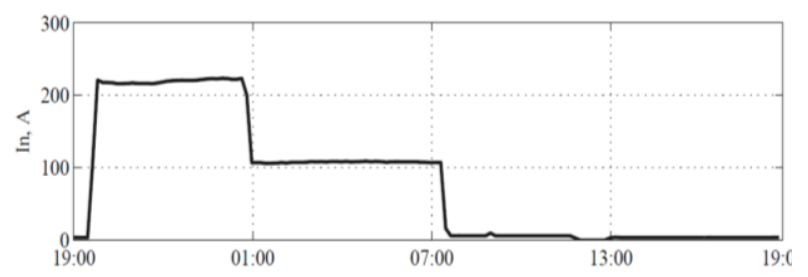

Fig. 1. Daily current variation in the neutral wire.

The harmonics cause malfunction of circuit breakers because of a high value of the cross ratio, transformer overheating because of additional eddy current losses, capacitor damage because of high values of harmonic currents, increase losses in the asynchronous motors, create transient overvoltages in the cosine capacitors, lead to malfunction of protection and automation systems and many other adverse effects [15-17]. The costs induced by harmonics amount to $5.4 \%$ of all the costs due to poor power quality [10].

\section{Damages from harmonics}

All adverse effects, i.e. damages, can be classified in the form presented in Fig. 2.

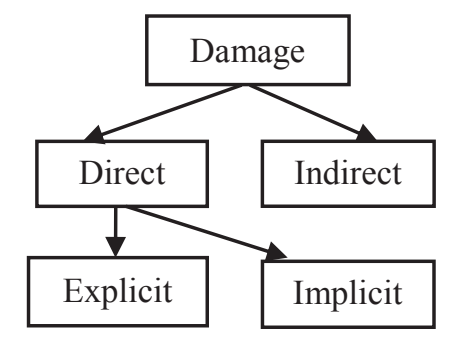

Fig. 2. Types of damages from harmonics.

The direct damage includes damages caused directly by equipment failures, malfunction of protection and automation systems, increase of power losses during its production, transmission, distribution and consumption. The direct damage can be divided into explicit and implicit damages. The explicit damage is linked to the effects, which can be seen and measured. The implicit damage is accumulated during a long time and can be estimated by the indirect indicators, special experiments and special calculations. The indirect damage comprises damages leading to violation of different production processes which cause quality degradation and decrease in output product quantity, drop in productivity and idle time of manpower. In addition, this damage includes an intangible damage that implies discomforts, for example, impossibility to switch a computer and enter an Internet because of poor voltage quality.

The effects of damages require additional financial expenses. According to the expert estimates the 
economic loss because of poor power quality amounts to billions dollars and euros annually $[10,11,18,19]$ :

- in the US in the process industry, financial services and food industry $-60-80$ billion USD,

- in the European Unity only in the trade and process industry -10 billion EUR, and the total loss is estimated at 100 billion EUR,

- in Russia "by the minimal estimate they are about 25 billion USD".

The financial losses can be reduced by power quality improvement, which is possible by detecting a degradation source first of all. The problem of determining the distorting load contribution to power quality degradation remains unsolved for many decades and is topical.

\section{Determination of the power quality distortion source and its contribution based on the harmonic active energies}

The nonlinear load receives active energy at the fundamental frequency (at the first harmonic). Part of this energy is consumed by load and part is converted into active energies at harmonics for orders $h>1$. The harmonic active energies of nonlinear load flow to the supply network, where they dissipate in equipment resistances, heat it and shorten service life. In the case of numerous nonlinear loads the harmonic active energies come from the supply network to the loads together with the active energy of the first harmonic and have adverse impacts. If the values of harmonic active energies flowing from the load to the supply network are determined, then it becomes possible to determine the nonlinear load contribution to power quality distortion. The paper [20] proposed that the asymmetrical consumer contribution to power quality distortion should be determined by the negative phase-sequence active energy.

We use an equivalent circuit to analyze harmonic active energies at the node of nonlinear load connection to the supply network that is presented in Figure 3 [21].

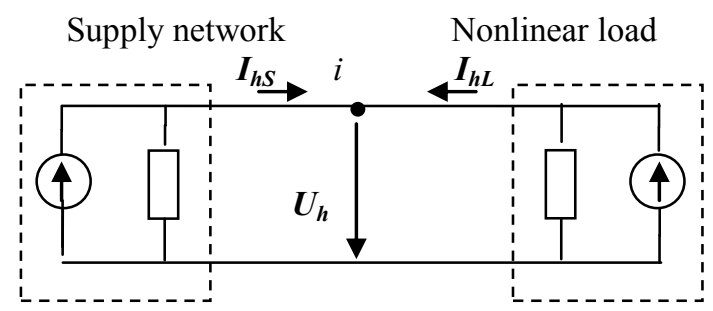

Fig. 3. An equivalent circuit of the supply network and nonlinear load for the $h$-th harmonic.

The notations used in the scheme are: $i$ - the number of the node;

$\boldsymbol{I}_{h S}$ - the vector of the $h$-th harmonic current of the supply network that is the resultant vector of the $h$-th harmonic current of all nonlinear loads available in the supply network except for current $\boldsymbol{I}_{\boldsymbol{h} \boldsymbol{L}}$;

$\boldsymbol{I}_{\boldsymbol{h} L}$ - the vector of the $h$-th harmonic current of the nonlinear load connected to the $i$-th node;
$\boldsymbol{U}_{\boldsymbol{h}}$ - the vector of the $h$-th harmonic voltage at the $i$-th node.

The resultant vector of the $h$-th harmonic current $\boldsymbol{I}_{\boldsymbol{h}}$ at the $i$-th node is determined by the vector sum of currents

$$
I_{h}=I_{h S}+I_{h L}
$$

The parameters of harmonic conditions depend on numerous factors: the wave effect appearing in transmission lines at the harmonic frequencies [22], the resonances emerging in the networks at harmonics [23], the values of phase angles of harmonic currents of nonlinear loads distributed in the network [24], the changes in network load and scheme, and the others, i.e. they are random values. Therefore, the values of current $\left(I_{h}\right)$, voltage $\left(U_{h}\right)$ and their phase angles $\left(\varphi_{U h}, \varphi_{I h}\right)$ should be obtained by measurements. The harmonic active powers are calculated based on the measured parameters

$$
P_{h}=U_{h} I_{h} \cos \varphi_{h},
$$

where $\varphi_{h}=\varphi_{U h}-\varphi_{I h}-$ phase displacement between the $h$-th harmonic voltage and current. The power flow direction is determined by the angle value $\varphi_{h}$ [25]. If $\varphi_{h}$ lies in the range 0 to $\pi / 2$ or $3 \pi / 2$ to $2 \pi$, the active power of the $h$-th harmonic flows from the network to the node connected load. If $\varphi_{h}$ lies in the range $\pi / 2$ to $3 \pi / 2$, then the active power of the $h$-th harmonic flows from the load to the network.

In the case of power supply from the source with sinusoidal voltage, the power flow of the first harmonic $\left(P_{1(+)}\right)$ is directed to the nonlinear load and most of this power is consumed by load to perform effective work $\left(P_{w}\right)$. Part of the active power of the first harmonic is converted by the nonlinear load into harmonic active powers that are directed from the load to the network $\left(P_{h(-)}\right)$. Then the active power of the first harmonic from the network to the load can be represented as

$$
P_{1(+)}=P_{w}+P_{h(-)}
$$

In the network with other nonlinear loads the harmonic active powers can be directed from the network to the load $\left(P_{h(+)}\right)$. The harmonic numbers of active powers $P_{h(-)}$ and $P_{h(+)}$ can be different. Thus, the harmonic active powers flowing through the node at any time interval are

$$
P=P_{w}+P_{h(+)}+P_{h(-)} .
$$

The parameters of harmonic conditions were measured during 24 hours with the time interval of one minute, which was taken into consideration in calculation of harmonic active powers. At the interval of one minute for one measurement the value of active power of any harmonic was assumed to remain invariable. Therefore, the active energy of any harmonic for the time interval of one minute is calculated as a product of harmonic active power by the time equal to one minute.

The presented theoretical principles were applied to the analysis of harmonic active powers flowing through the connection node of the aluminum smelter block to 
the $220 \mathrm{kV}$ network. Figure 4 demonstrates the total time of harmonic active power flow for 24 hours through the node from the aluminum smelter block to the supply network (Time $P_{h(-)}$ ), and from the supply network to the aluminum smelter block (Time $P_{h(+)}$ ).

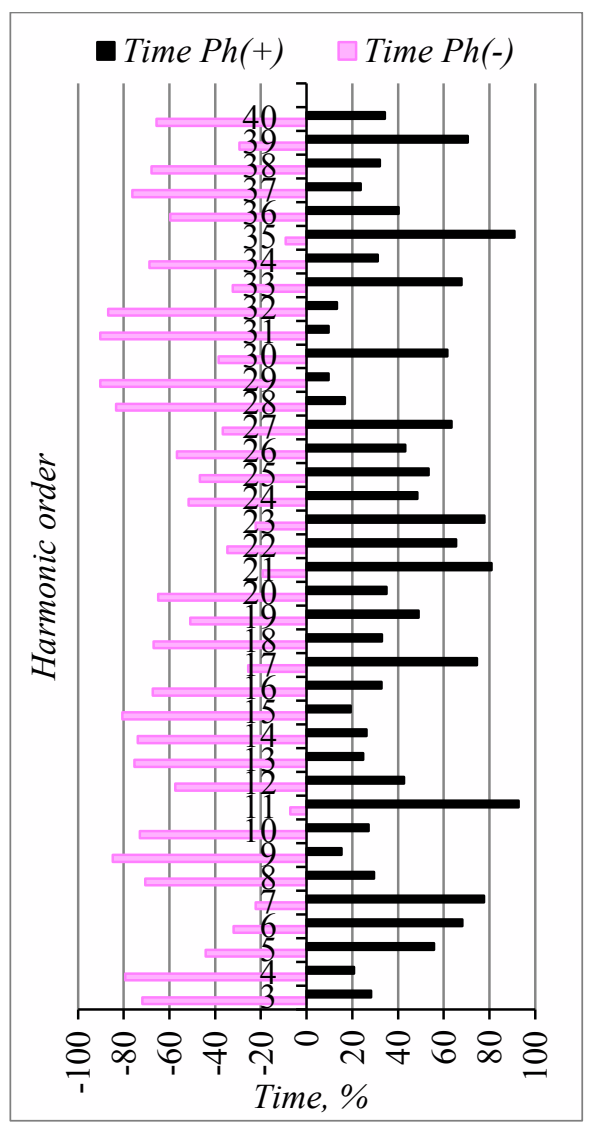

Fig. 4. Time of harmonic active power flow through the connection node of the aluminum smelter block to the supply network in two directions.

Table 2 presents statistical estimates of harmonic active powers, i.e. detrimental powers $P_{d(-)}$ and $P_{d(+)}$ [26] flowing through the connection node in both directions. The harmonic active powers are defined as

$$
\begin{gathered}
P_{d(-)}=\sum_{h=2}^{40} P_{h(-)}, \\
P_{d(+)}=\sum_{h=2}^{40} P_{h(+)} .
\end{gathered}
$$

Values $P_{d(-)}$ and $P_{d(+)}$ were calculated for 1440 measurements.

Table 2. Statistical estimates of harmonic active powers, $\mathrm{kW}$, and time of their flows, hours.

\begin{tabular}{|l|c|c|c|}
\hline \multirow{2}{*}{ Parameter } & \multicolumn{3}{|c|}{ Phase } \\
\cline { 2 - 4 } & $\mathrm{A}$ & $\mathrm{B}$ & $\mathrm{C}$ \\
\hline$P_{\operatorname{dmax}(-)}$ & 55.0 & 71.4 & 61.2 \\
\hline$P_{\min (-)}$ & 0.1 & 0.4 & 0.6 \\
\hline$P_{\operatorname{daver}(-)}$ & 11.4 & 19.5 & 9.0 \\
\hline$t_{h(-)}$ & 528.6 & 499.9 & 549.2 \\
\hline$P_{\max (+)}$ & 59.4 & 22.4 & 72.9 \\
\hline$P_{d \min (+)}$ & 1.5 & 1.1 & 1.1 \\
\hline$P_{\operatorname{daver}(+)}$ & 21.2 & 22.4 & 25.9 \\
\hline$t_{h(+)}$ & 407.4 & 436.1 & 386.8 \\
\hline
\end{tabular}

The Table shows that the values of average harmonic active powers at three phases, which flow from the load to the supply network, are lower than the similar values of powers flowing from the supply network to the load. On the other hand, the time of harmonic active power flows to the supply network is longer than the time of harmonic active power flows to the load.

Table 3 presents the calculated active energies in both directions for some characteristic harmonics and the total energies for 39 harmonics at three phases for 24 hours of measurements. In the Table $W_{d(-)}, W_{d(+)}$ are harmonic active energies flowing to the supply network and load, respectively. From the Table it follows that during 24 hours the aluminum smelter block generates $686.4 \mathrm{~kW} \cdot \mathrm{h}$ of active energy of the 13-th harmonic to the supply network, but receives $1185.0 \mathrm{~kW} \cdot \mathrm{h}$ of active energy of the 11-th harmonic from the supply network. Taking into account the energy of 39 harmonics, the aluminum smelter block generates $957.0 \mathrm{~kW} \cdot \mathrm{h}$ of harmonic active energy to the supply network, and receives $1669.7 \mathrm{~kW} \cdot \mathrm{h}$.

Table 3. Harmonic active energies, $\mathrm{kW} \cdot \mathrm{h}$.

\begin{tabular}{|c|c|c|}
\hline$h$ & $W_{d(-)}$ & $W_{d(+)}$ \\
\hline 11 & 44.0 & 1185.0 \\
\hline 13 & 686.4 & 157.0 \\
\hline 23 & 11.3 & 46.6 \\
\hline 25 & 19.4 & 31.8 \\
\hline 35 & 7.1 & 173.6 \\
\hline 37 & 67.2 & 10.4 \\
\hline $2-40$ & 957.0 & 1669.7 \\
\hline
\end{tabular}

In addition to the active energy of positive sequence of the first harmonic, some up-to-date measuring instruments of power quality indices and smart meters fix the active energy of all harmonics, which makes it possible to calculate the total distorting active energy. This energy can be used to determine overpayment or underpayment for electricity by consumers. If instead of the total harmonic active energy the instruments and smart meters measure harmonic active energies flowing in different directions separately, this will allow determination of the value of consumer contribution to power quality distortion. In such a case the harmonic active energies could be applied to assess the nonlinear load contribution to power quality distortion and taken into consideration by electricity rate charge. If the harmonic active energies are fed from the network to the load, the enterprise could be granted a rate discount, for example, as in [6]. This issue should be elaborated thoroughly and tested at the first stage on the basis of the information obtained during continuous monitoring of harmonic condition parameters and power quality indices during a long period of time.

\section{Conclusion}

In Russia the power quality is not given due attention because of imperfection of the legislative and legal documents. Violations of the requirements of GOST 32144-2013 are of large-scale and systematic 
character in all national power companies. Practically the tasks on provision of the levels of harmonic voltages and negative sequence of the first harmonic are not stated and solved.

The poor power quality causes damages to electrical equipment of electricity consumers and suppliers, interruptions of power supply to consumers, and as a consequence, financial losses to them.

The need to immediately tackle the power quality as the problem of the national importance became urgent, since the number of distorting electrical equipment of consumers and complaints about poor power quality increased.

Under market relations in electric power industry, it is necessary to develop the economic mechanism of maintaining the power quality, which will comply with the requirements of GOST 32144-2013.

\section{References}

1. CIGRE. Working Group 37.28, Quality of supply customer requirements, (June, 2001)

2. Federal law of RF of 27.12.2002 №184-Ф3 “On technical regulation"

3. Federal law of RF of 26.03.2003 № 35-Ф3 “On electric power industry"

4. GOST 13109-97. Electric energy. Electromagnetic compatibility of technical equipment. Power quality limits in public power supply systems.

5. The rules of consumer connection to the public network with respect to the effect on power quality, Promyshlennaya energetika 8, 45-48 (1991).

6. The rules of applying rate discounts and surcharges for power quality, Promyshlennaya energetika 8, 49-51 (1991).

7. V.A. Ovseichuk, Novosti elektroenergetiki 1(91), (2015), http://news.elteh.ru/arh/2015/91/03.php

8. GOST 32144-2013. Electric energy. Electromagnetic compatibility of technical equipment. Power quality limits in public power supply systems, (2014).

9. V. Fishman, Novosti elektrotekhniki 5(29), (2004), http://news.elteh.ru/arh/2004/29/06.php

10. R. Targosz, D. Chapman, (2015),

http://www.leonardo-energy.org/resources/297/the-costof-poor-power-quality-5800e490fle14

11. A. de Almeida, L. Moreira, J. Delgado, Power quality problems and new solutions, Proceedings of ICREPQ, (2013).

12. S.S. Smirnov, L.I. Kovernikova, Promyshlennaya energetika 8, 45-48 (2000).

13. Presentation of Public Joint Stock Company "Rosseti - Ministry of Energy", https://minenergo.gov.ru /system/download-pdf.

14. M.O. Chernyshov, V.H. Dovgun, V.V. Novikov, S.V. Brutsky, Energy of Russia in XXI century, Innovative development and control, Proceedings of Russian Conference, 225-228 (2015), http://isem.irk.ru/energy21/papers/Чернышов\%20MO\%
20и\%20др\%20Проблемы\%20обеспечения\%20качеств a\%20электроэнергии.pdf.

15. R. Hartungi, L. Jiang, Investigation of power quality in health care facility. Proceedings of ICREPQ, (2010).

16. L.I. Kovernikova, Estimation of damage from higher harmonic, Proccedings of the 3rd International Workshop Liberalization and Modernization of Power Systems, 201-204 (2006).

17. V.N. Gromov, Power quality control: Proceedings of the International Scientific and Practical Conference, 85-92 (Moscow, 2014).

18. L.N. Dobrusin, Report at the VI All-Russian Energy Forum "Energy of Russia in XXI century, Moscow, State Kremlin Palace, (2008).

19. Economic evaluation of power quality. IEEE Power engineering. Review, 22, (2002).

20. V.S. Sokolov, M.A. Ermilov, A.V. Serkov, A.V. Gromov, N.V. Chernyshova, Promyshlennaya energetika 8, 52-55 (2000).

21. L.I. Kovernikova, Electrichestvo 3, 12-20 (2017).

22. A.E. Emanuel, Power definitions and physical mechanism of power flow, (John Wiley \&Sons, 2010).

23. J. Arrilaga et al. Harmonics in electrical systems: Translation from English, (Energoatomizdat, 1990).

24. W.E. Kazibwe, T.H. Ortmeyer, M.S.A.A. Hammam, IEEE Transactions on PD 4, 621-628 (1989).

25. R.H. Stevens, IEEE Transactions on PAS 102, 3018-3021 (1983).

26. L.S. Czarnecki, IET Generation, Transmission \& Distribution 1, 1-7 (2012). 